Gut, 1975, 16, 957-960

\title{
Postprandial osmotic and fluid changes in the upper jejunum after truncal vagotomy and drainage in $\operatorname{man}^{1}$
}

\author{
J. G. TEMPLE', ALMA BIRCH, AND R. SHIELDS 3 \\ From the Department of Surgery, University of Liverpool, Liverpool
}

SUMMARY The changes in osmotic pressure and the degree of marker dilution in the jejunal lumen, after a hypertonic meal, have been studied in patients after truncal vagotomy and drainage, with and without diarrhoea, using an intraluminal intubation technique. The results suggest that neither the emptying of a hyperosmotic load from the stomach, nor its subsequent dilution in the jejunum have an important role in post-vagotomy diarrhoea.

The cause of diarrhoea after vagotomy remains obscure. Precipitate gastric emptying has been observed after a truncal vagotomy and drainage procedure (McKelvey, 1970), particularly in those patients with diarrhoea (Colmer et al., 1973). Normally the intact pylorus protects the upper small bowel from excessive osmotic loads (Sessions et al., 1962), but a vagotomy and drainage procedure may alter or by-pass the normal gastric emptying mechanism. The present study was designed to determine whether, after truncal vagotomy and drainage, the upper jejunum receives osmotically irritating fluid, and, if so, the relationship of this phenomenon to post vagotomy diarrhoea.

\section{Methods}

\section{PATIENTS}

Thirty patients were studied after truncal vagotomy and drainage for duodenal ulceration. The type of operation performed is shown in Table 1. After operation, 13 of these individuals had diarrhoea, defined as the passage of three or more liquid stools per day. All the post-vagotomy subjects were studied at least three months after operation, and informed consent was obtained in every case.

As a contrast group, 13 individuals, who had not had any previous gastric operation were studied. Six

${ }^{1}$ Based on a communication to the Surgical Research Society, January 1974.

'Present address: J.G.T., Senior Lecturer, Department of Surgery, Hope Hospital, Salford.

Address for reprint requests : R. S., Department of Surgery, Elizabeth Street, P.O. Box 147, Liverpool L69 3BX.

Received for publication 30 July 1975.

\begin{tabular}{llrl}
\hline & & No. & Average age $(y r)$ \\
\hline Contrast & & 13 & $48 \cdot 3$ \\
& Normal & 6 & $44 \cdot 8$ \\
Post-vagotomy & Active DU & 7 & $50 \cdot 7$ \\
diarrhoea-free & & 17 & $48 \cdot 3$ \\
& TV + P & 6 & $48 \cdot 8$ \\
Post-vagotomy & TV + PGE & 11 & $47 \cdot 9$ \\
diarrhoea & & 13 & $52 \cdot 7$ \\
& TV + P & 8 & $54 \cdot 1$ \\
& TV + PGE & 5 & $51 \cdot 4$ \\
\hline
\end{tabular}

\section{Table 1 Patients studied}

Contrast: normal and active duodenal ulcer patients. TV + P: truncal vagotomy and pyloroplasty.

TV + PGE: truncal vagotomy and posterior gastrojejunostomy.

were completely free of any gastrointestinal disease and seven had an uncomplicated duodenal ulcer.

\section{TECHNIQUE}

Meal marker studies were performed in these subjects by intubating the upper jejunum. A long narrow, single lumen polyvinyl tube of $2.5 \mathrm{~mm}$ internal diameter was introduced through the mouth, and allowed to advance until its tip lay just beyond the ligament of Treitz (Blankenhorn et al., 1955), the position being checked by radiographic screening. In patients with a gastrojejunostomy, the tube was always positioned through the stoma and into the efferent loop. The tube was not fixed to the patient at any time, so that it could advance during the course of the test and thus obviate shortening of the bowel upon it (Cook and Carruthers, 1974):

After a 12 hour fast, each subject drank a $300 \mathrm{ml}$ 
fluid test meal consisting of cows' milk containing $26 \mathrm{~g}$ sucrose and $4 \mathrm{ml} \mathrm{Cr}^{51}$ ethylene diamine tetra acetate (EDTA), as a non-absorbable marker (Brigham et al., 1970). The subjects consumed this meal over a period of three to five minutes and were seated comfortably in an arm chair throughout the test period of $2 \frac{1}{2}$ hours. Samples were obtained in 30 minute aliquots by continuous syphonage and collected under oil in flasks chilled by surrounding ice. The osmolality of each aliquot was measured immediately by freezing point depression. Subsequently, each sample was centrifuged and the concentration of $\mathrm{Cr}^{51}$ EDTA in the supernatent estimated by gamma counting. Statistical analyses were performed using Student's $t$ test. Results are expressed as means $\pm \mathrm{SEM}$.

\section{Results}

The osmolality and concentration of the nonabsorbable marker in jejunal aspirates were not statistically different in the healthy subjects and the unoperated duodenal ulcer patients, and, therefore, these results have been grouped together to form a contrast group for comparison with those from the postoperative patients (Table 2). In Figs. 1 and 2, the shaded area represents mean \pm SEM for this contrast group.

\section{OSMOLALITY}

The osmolality of the test meal was $590 \mathrm{mOsm} / \mathrm{kg}$. In one of the post-vagotomy subjects resting jejunal juice was obtained before ingestion of the meal. The osmolality of this sample was $280 \mathrm{mOsm} / \mathrm{kg}$.

In the contrast group, the mean osmolality $( \pm$ $\mathrm{SE})$ at 30 minutes was $375 \pm 9 \mathrm{mOsm} / \mathrm{kg}$. It decreased progressively throughout the test period to reach a final value of $266 \pm 4 \mathrm{mOsm} / \mathrm{kg}$ (Table 2).

In general, the osmolality of the jejunal content in patients after vagotomy, whether they had diarrhoea or not, did not differ markedly from the contrast group. Patients after vagotomy but without diarrhoea had a higher mean osmolality at $\mathbf{3 0}$

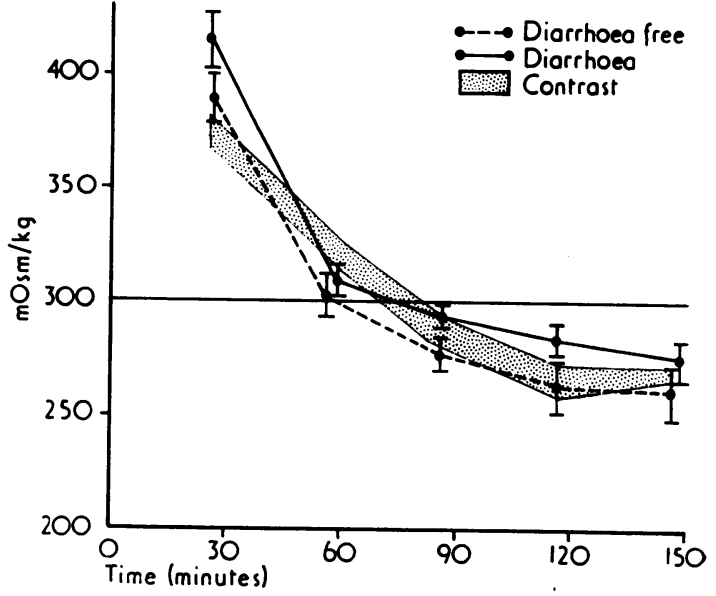

Fig. 1 Osmolality of upper jejunal aspirates in contrast group (shaded area) and in the patients after truncal vagotomy with and without diarrhoea. Means \pm SE are shown.

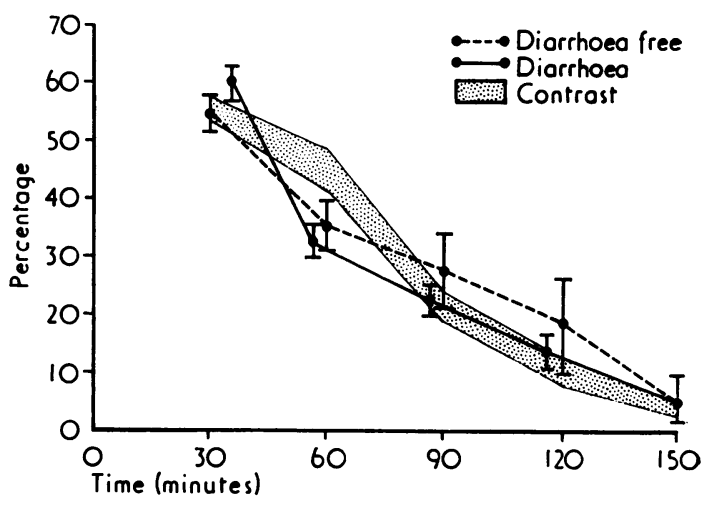

Fig. 2 Concentration of $\mathrm{Cr}^{51}$ EDTA in each sample expressed as a percentage of $\mathrm{Cr}^{51}$ ingested in test meal. Means $\pm S E$ are shown.

\begin{tabular}{|c|c|c|c|c|c|c|}
\hline \multirow[t]{2}{*}{ Time after end of meal (min) } & \multicolumn{3}{|c|}{ Osmolality (mOsm/kg) } & \multicolumn{3}{|c|}{ Marker dilution $\left(\mathrm{Cr}^{51} \% \mathrm{Cr}^{51}\right.$ in test meal $)$} \\
\hline & $\begin{array}{l}\text { Healthy } \\
\text { subjects }\end{array}$ & Active $D U$ & $\begin{array}{l}\text { Contrast } \\
\text { (healthy } \\
\text { subjects } \\
\text { active } D U \text { ) }\end{array}$ & $\begin{array}{l}\text { Healthy } \\
\text { subjects }\end{array}$ & Active $D U$ & $\begin{array}{l}\text { Contrast } \\
\text { (healthy } \\
\text { subjects } \\
\text { active DU) }\end{array}$ \\
\hline $\begin{array}{r}30 \\
60 \\
90 \\
120 \\
150\end{array}$ & $\begin{array}{l}384 \pm 16 \\
336 \pm 11 \\
293 \pm 11 \\
274 \pm 7 \\
273 \pm 8\end{array}$ & $\begin{array}{l}368 \pm 8 \\
315 \pm 7 \\
278 \pm 5 \\
257 \pm 8 \\
262 \pm 3\end{array}$ & $\begin{array}{l}375 \pm 9 \\
325 \pm 7 \\
285 \pm 6 \\
264 \pm 6 \\
266 \pm 4\end{array}$ & $\begin{array}{r}61.0 \pm 3.9 \\
49.6 \pm 5.2 \\
24.0 \pm 4.2 \\
9.4 \pm 2.3 \\
4.1 \pm 0.9\end{array}$ & $\begin{array}{r}53.2 \pm 2.3 \\
42.7 \pm 4.8 \\
20.3 \pm 3.2 \\
8.7 \pm 2.0 \\
5.5 \pm 1.8\end{array}$ & $\begin{array}{r}56.7 \pm 2.4 \\
45.8 \pm 3.5 \\
21.9 \pm 2.5 \\
9.1 \pm 1.4 \\
4.9 \pm 1.1\end{array}$ \\
\hline
\end{tabular}

Table 2 Jejunal osmolality and marker concentrators: contrast group 
minutes but a lower osmolality at 60 minutes than the contrast group (Fig. 1). However these differences are not statistically significant.

Patients with diarrhoea had a significantly greater osmolality of jejunal content at $\mathbf{3 0}$ minutes than the contrast group $2 \mathrm{P}<\cdot 025$ ), but this result was not statistically different from the osmolality measured in the post vagotomy group without diarrhoea. For the remainder of the test period, the post vagotomy subjects with and without diarrhoea showed essentially similar values for jejunal osmolality.

CONCENTRATION OF CR ${ }^{51}$ EDTA

In all the groups tested, there was a progressive decrease in the concentration of $\mathrm{Cr}^{51}$ EDTA in each sample, expressed as a percentage of the concentration ingested in the test meal.

In the contrast individuals, the value at $30 \mathrm{~min}$ utes was $56.7 \pm 2.4 \%$ and at 150 minutes $4.9 \pm$ $3.2 \%$ (Table 2).

After vagotomy, patients with and without diarrhoea had a similar concentration of $\mathrm{Cr}^{51}$ EDTA at 30 minutes to the contrast group (Fig. 2). However, both postvagotomy groups had a significantly lower concentration of the non-absorbable marker than the contrast group at 60 minutes $(2 \mathrm{P}<.005$ in the case of those with post-vagotomy diarrhoea and $2 \mathrm{P}<.001$ for those who were diarrhoea free). Nevertheless, there is no difference between the two postoperative groups themselves at this or any other time during the test period. For the remainder of the test, subjects with and without diarrhoea after vagotomy had similar concentrations of $\mathrm{Cr}^{51}$ to the contrast group.

\section{Discussion}

We have studied the osmotic pressure and nonabsorbable marker dilution that occurs in the upper jejunal lumen after ingestion of a hyperosmotic fluid meal, in patients after vagotomy with and without diarrhoea, and in a group of subjects who have not had any gastric operation. Our studies do not show any evidence that a grossly hyperosmotic load is presented to the upper jejunum of patients with post-vagotomy diarrhoea. Indeed, there is no significant difference between the osmolalities measured in any of the patients with or without diarrhoea after truncal vagotomy and drainage. It is, however, interesting to note that, even in normal subjects, the upper small bowel content is not always iso-osmotic after a meal as has previously been suggested (Miller, 1949; Fordtran and Locklear, 1966; Fordtran, 1967). Apparently, nearly one hour is necessary for isotonicity to be restored to the upper iejunum.

The concentration of the non-absorbable marker gives an estimation of the relative volume changes occurring in the small bowel lumen (Fields and Duthie, 1965; Fordtran and Locklear, 1966). The progressive fall in concentration of $\mathrm{Cr}^{51}$ seen in all the subjects tested indicates that dilution of the hyperosmotic meal occurred by the time it reached the upper jejunum. From the present study, it appears that the quantity of fluid that is added to the meal as it passes around the duodenal loop and into the upper small bowel is similar in all the patients after truncal vagotomy and drainage, irrespective of the presence or absence of diarrhoea. The lower concentration of the marker in these two groups of patients compared with the contrast group at 60 minutes after ingestion of the meal indicates that a greater relative dilution has occurred at this time in all the post-vagotomy subjects. However, these changes are not of any great biological importance and it would seem that the upper small bowel is very adaptable to a wide range of osmolalities even when the normal emptying mechanism is disturbed or by-passed by a drainage procedure.

The meal used in this study was designed to be hyperosmotic but to have an osmotic pressure similar to that of food ingested in a normal diet (Fordtran and Loclear, 1966). Many of the previously reported studies on post-vagotomy diarrhoea have utilized oral ingestion or even intra-jejunal instillation of solutions with an osmotic pressure in excess of 1000 $\mathrm{mOsm} / \mathrm{kg}$, such as $300 \mathrm{ml} 50 \%$ glucose. These are surely non-physiological challenges to the osmotic capacity of the upper small bowel. Sessions et al. (1962) and Fenger (1965) have both shown that, even in normal subjects, postprandial symptoms will be provoked if a large enough oral challenge is given. It is often overlooked that patients experience post-vagotomy diarrhoea while on a normal diet.

A meal marker technique of the type used in this study has many limitations. Factors such as gastric emptying, intestinal flow rate, and intestinal motility are quite uncontrolled. Moreover, the quantity of biliary and pancreatic juices added to the duodenal content is quite unknown. However, the presence of a tube in the upper gastrointestinal tract interferes in no way with normal physiological processes (Meeroff et al., 1973; Moberg, 1974) and, although quantitive recovery of aspirated material is not essential, it is possible to evaluate the relative changes occurring in the small bowel lumen with this technique.

Despite the limitations of the method, this study shows quite clearly that, when diarrhoea is encountered after truncal vagotomy and drainage, it is not due to a vast outpouring of fluid into the jejunal lumen in response to the empyting into the upper small bowel of osmotically irritating fluid. 
We are indebted to $\mathrm{Mr}$ J. B. McFarland for allowing us to study some of his patients and to Dr Anne Hardy-Smith and Mr Gerald Lepts for their technical assistance. Financial support was provided by the Medical Research Committee of the Mersey Regional Health Authority and the Medical Research Council.

\section{References}

Blakenhorn, D. H., Hirsch, J., and Ahrens, E. H. Jr. (1955). Transintestinal intubation: technic for measurement of gut length and physiological sampling at known loci. Proceedings of Experimental Biology (N.Y.), 88, 356-362.

Brigham, K. L., Banwell, J. G., Pierce, N. F., Mitra, R. C., Fedson, D. S., and Mondal, A. (1970). Indicator dilution studies in the small bowel of patients with cholera diarrhoea, II, comparisons of absorbable and "poorly absorb able" substances. Johns Hopkins Medical Journal, 127, 107. 118.

Colmer, M. R., Owen, G. M., and Shields, R. (1973). Pattern of gastric emptying after vagotomy and pyloroplasty. British Medical Journal, 2, 448-450.

Cook, G. C., and Carruthers, R. H. (1974). Reaction of human small intestine to an intraluminal tube and its importance in jejunal perfusion studies. Gut, 15, 545-548.

Fenger, H. J. (1965). The dumping disposition in normal persons. Acta Chirurgica Scandinavica, 129, 201-210.

Fields, M., and Duthie, H. L. (1965). Effect of vagotomy on intraluminal digestion of fat in man. Gut, 6, 301-310.

Fordtran, J. S. (1967). Speculations on the pathogenesis of diarrhoea. Federation Proceedings, 26, 1405-1414.

Fordtran, J. S., and Locklear, T. W. (1966). Ionic constituents and osmolality of gastric and small-intestinal fluids after eating. American Journal of Digestive Diseases, 11, 503-521.

McKelvey, S. T. D. (1970). Gastric incontinence and postvagotomy diarrhoea. British Journal of Surgery, 57, 741747.

Meeroff, J. C., Go, L. W. V., and Phillips, S. F. (1973). Gastric emptying of liquids in man. Proceedings of the Staff Meetings of the Mayo Clinic, 48, 728-732.

Miller, T. G. (1949). Intestinal intubation. Cleveland Clinic Quarterly, 16, 68-73.

Moberg, S. (1974). Gastric emptying and duodenal digestion before and after partial gastrectomy and selective proximal vagotomy. Scandinavian Journal of Gastroenterology, suppl. no. 24.

Sessions, R. T., Reynolds, V. H., Ferguson, J. L., and Scott, H. W. Jr. (1962). Correlation between intraduodenal osmotic pressure changes and $\mathrm{Cr}^{51}$ blood volumes during induced dumping in men with normal stomachs. Surgery, 52, 266-277. 